\title{
Cooking and Lighting Fuels Clusters in Katsina: Progression of Vulnerability Dread on Households
}

\author{
Murtala Rabiu $^{1 *}$, Dr Gamal A El-Gasim², Dr Mohamed Al-Sheik ${ }^{2}$ \\ ${ }^{I}$ Geography Department, School of Secondary Education Arts and Social Sciences, Isa Kaita College of \\ Education, P.M.B 5007, Dutsinma, Katsina State Nigeria \\ ${ }^{2}$ Department of Geography and History, Faculty of Education, Hantoup, University of Gezira, Gezira State \\ Sudan
}

*Corresponding Author: Murtala Rabiu, Geography Department, School of Secondary Education Arts and Social Sciences, Isa Kaita College of Education, P.M.B 5007, Dutsinma, Katsina State Nigeria

\begin{abstract}
PAR model for disaster management has awakened researchers to join the race particularly in natural occurrences. It ponders disaster as the product of processes generating vulnerability and the natural hazard events however, it is obvious that disaster crop up as a result of human demographic composition resulting to households being at risk. This research hence, evaluates the progression of vulnerability. Cooking and lighting fuel used were sourced from population and housing census Nigeria. Location quotient was used to ascertain spatial concentration. The progression of vulnerability evaluated indicates forces of political instability, corruption and lack of basic infrastructures, being the causes of inadequate provision of cooking and lighting fuels in Katsina state. There is high spatial clustering of Gas LQ 2.45 and Electricity $L Q$ 1.46. This implies high degree of vulnerability to gas explosions fire outbreak and electric sparks. The common lighting fuel is kerosene LQ 1.14 using bush lamps, this cause pervasive living in darkness by the households and trail connected insecurities that guaranteed vulnerability. This research has implication in disaster management, crime prevention and good literature in the academia. We recommend GIS pattern analysis, enactment of legislations for indiscriminate felling of trees and the need for alternative sources such as provision of steady electricity for safe cooking and lighting.
\end{abstract}

Keywords: Cooking fuel, Cluster, Household, Lighting fuel, Vulnerability.

\section{INTRODUCTION}

Since PAR model for disaster management transpired in academic circle, scholars have been striving to seek its usability more in to natural occurrences for instance climate change (Füssel 2007; Awal 2015), because the model considers disaster as the product of processes generating vulnerability and the natural hazard events (Blaikie et al. 1994). The dispute here is that, does disaster never happen as a result of human demographic composition leading to households being at risk? It is hence fascinating to foster answer to such question, though efforts were made in incorporating demography by pondering sustainable livelihood in post disaster recovery plan (Alexander, Chan-Halbrendt, and Salim 2006).

In a full scale disaster management, the scenario is often trail in phases. These include pre-disaster phase where prevention and mitigation measures are taken, prediction, warning as well preparedness. The second phase is during disaster, this rely to a great extent on response capabilities and local coping aided by government, public and non-governmental organisations. The pos-disaster phase engulfs evaluation, reconstruction and recovery. These disaster management phases serve as window through which research can be carried out. The most stunning phase is the pre-disaster phase which if well organized usually prevents the occurrence of second or both remaining phases as the case may be. This research focuses on pre-disaster events due to its advantages meant to cutback the menace of remaining disaster management phases.

There are quite a number of studies to solve shortfalls in pre-disaster phase, the strengthening of Istanbul's urban highway system against earthquake risk (Peeta et al. 2010) is a good example, whose links have been rooted with random failures. This could provide practical insight for decision makers in managing earthquake risk. Some pre-disaster measures propounded due to post-disaster experience in order to avert feature happenings, the northern Tokyo bay earthquake experienced, basis pre- 
disaster restoration concept (Nakabayashi, Aiba, and Ichiko 2008). This involves series of connected activities from estimating restoration damage scenarios of current urban condition to implementing community-based disaster-prevention development "Machizukiri" in Japanese, all to minimize restoration requirements.

During disaster events, the needed response is first how to save lives and then properties from lost. An emergency logistics distribution is seen important for the ease of disaster repercussions in affected areas, Sheu (2007) presents a hybrid fuzzy clustering-optimization approach to the operation of emergency logistics co-distribution responding to the urgent relief demands in the crucial rescue period. In the same vein of logistics problem (Yi and Kumar 2007; Yi and Özdamar 2007; Barbarosoğlu and Arda 2004) According to Ingram et al., (2006) the post-disaster manifesto that are aimed at sustainable re-development to be reported by analysis of the components of vulnerability that comprise a system and how these can be most effectively impacted during the separate short-term and long-term phases of rebuilding. The post-disaster reconstruction and its impact on small scale approaches (Lyons 2009; Kennedy et al. 2008), problem of shelter in post-disaster (Boano 2009), the correct and fallacy of postdisaster events (Davidson et al. 2007) and its success and fiasco (Oliver- Smith 1991)

This research seek to use PAR model unsafe conditions through pressure and release taking cooking fuel and lighting fuel as sub-set of demographic variable to analyze and demonstrate if households adopting the available main types of cooking and lighting fuels highlighted are vulnerable to disaster in Katsina State Nigeria. The main types of cooking and lighting fuel applicable to both cooking and lighting fuels in the study area are Electricity, Gas, Kerosene and Solar. Nigeria with over $180 \mathrm{~m}$ people and an annual population growth of $2.7 \%$ have been managing two major sources of electricity generation, the hydroelectricity generation and thermal power generation. The thermal generation only generate 301MW (Oyedepo et al. 2014), as of January 42017 Nigeria only generate 3,959MW which by January 222017 dropped drastically to 2,662MW (NAN 2017). The same problem with gas, with miniature supply and confined to the southern part of the country. The price too exuberant makes it unaffordable for rural dwellers. The only four existing refineries to supply kerosene have not been working for long, the country rely on product importation which is not enough to cater for local consumption. Solar power generation has not been widely accepted with high cost of installation. It is therefore, apparent that Nigerian households and Katsina state in particular suffer in their striving efforts to access feasible cooking and lighting fuels.

\section{THE DISASTER}

The irregular supply of electricity has been a causative agent of many fatal fire disaster outbreaks in Nigeria Katsina state inclusive. The supply is not steady and uneven, sometimes with high voltage as a result ignite spark and cause fire disaster outbreak. Households have been living in total darkness, this amplified insecurity disaster giving hoodlum's opportunity for burglary and its associated criminal acts. Households hence, left with options of using kerosene for cooking through the use of stoves and bush lamps for lighting, and study show that large proportion of burns are the results of using kerosene for both cooking and lighting (Peck et al. 2008). The problem leads to complications in antenatal care, in Maiduguri teaching hospital a survey of ten years period revealed a $92.9 \%$ pregnancy lost as a result of severe burns rooted from poor cooking and lighting fuels used, and 47.6\% maternal mortality with sepsis as the most common cause of the disaster (Chama and Na'Aya 2002). These gives a short-term challenge, in a long term basis a substantial proportion of Nigerian population comes from rural areas, the economic status of these households has forced them to use other alternatives for cooking and lighting fuel demands, in Katsina state 54,435 households uses candle for lightings. In the alternative for cooking fuel, $63.7 \%$ of the total households use firewood (NPC 2009), this is an alarming rate being the state prone to desert encroachments, and the trend is connected to continual felling of trees for fuel wood (Audu 2013). These trends therefore, could generate long term vulnerability of hunger, flooding, poor water quality, migration and poverty to households if remedy measures to this disaster have not been put in use.

\section{Materials ANd Methods}

\subsection{Data}

The distribution of regular households by types of cooking fuel and that of lighting fuel were sourced from demographic component of National Population and housing census of Nigeria and used in this 
study and shown on Table 1. There are a total of 1,066,316 households across the state. A household composed of one or more people who occupy a housing unit. In rural Katsina state, most of the family practice extended type of family where a chain of relatives reside in the same housing unit most a time with single entry in to the house and a single toilet to be used by all the household members. National Population Census of Nigeria conducts routine population and housing census. Data generated through these surveys are made available for use by including academia. The surveys are periodic after each ten years period, the last the country witness was in 2006 the expected date for next surveys was 2016 due to economic and political factors these surveys were not conducted as scheduled. The 2006 data is the only available data at disposal for research of this kind. The surveys requires huge amount of money for the temporary personnel and logistic cost to ensure accuracy and coverage, this makes it more reliable for a comprehensive research rather than primarily sourcing the data by a researcher though it can be sourced primarily for data validation using sampling techniques.

Table1. Distribution of Cooking and Lighting Fuels in Katsina State

\begin{tabular}{|l|l|l|}
\hline \multicolumn{1}{|c|}{ Type } & \multicolumn{1}{c|}{ Cooking Fuel } & \multicolumn{1}{c|}{ Lighting Fuel } \\
\hline Electricity & 185,199 & 249,776 \\
\hline Gas & 25,312 & 14,842 \\
\hline Kerosene & 139,926 & 753,408 \\
\hline Firewood & 679,134 & - \\
\hline Coal & 23,842 & - \\
\hline Animal dung/Plants husk & 7,885 & - \\
\hline Solar & 3,130 & 5,981 \\
\hline Candle & - & 54,435 \\
\hline Other & 1,888 & 5,874 \\
\hline
\end{tabular}

\subsection{Study Area}

Katsina state as outlined in Figure 1 is in the North West region of Nigeria and was created out of Kaduna state on September 23, 1987. It has a total land area of $9,341 \mathrm{mi}^{2}$ and fifth most populous state in Nigeria with population of $5,792,578$ people. It is located between $12^{0} 59^{\mathrm{I}} 52^{\mathrm{II}} \mathrm{N}$ and $7^{0} 35^{\mathrm{I}} 58^{\mathrm{II}} \mathrm{E}$ and shares border with Niger Republic to the North. It has Sahel savannah vegetation with patches of grasses, fewer trees and pressing desert encroachment. People in the state are predominantly farmers they are Hausa-Fulani by tribe and majority Muslims with minority Christians mostly migrant from southern part of the country. Rainfall is scanty begins in late April and seized early September forcing farmers to cultivate selected cereals and cash crops that can adapt to limited period of rainfall per annum in conjunction with the soil type in the state which is more of sandy soil.

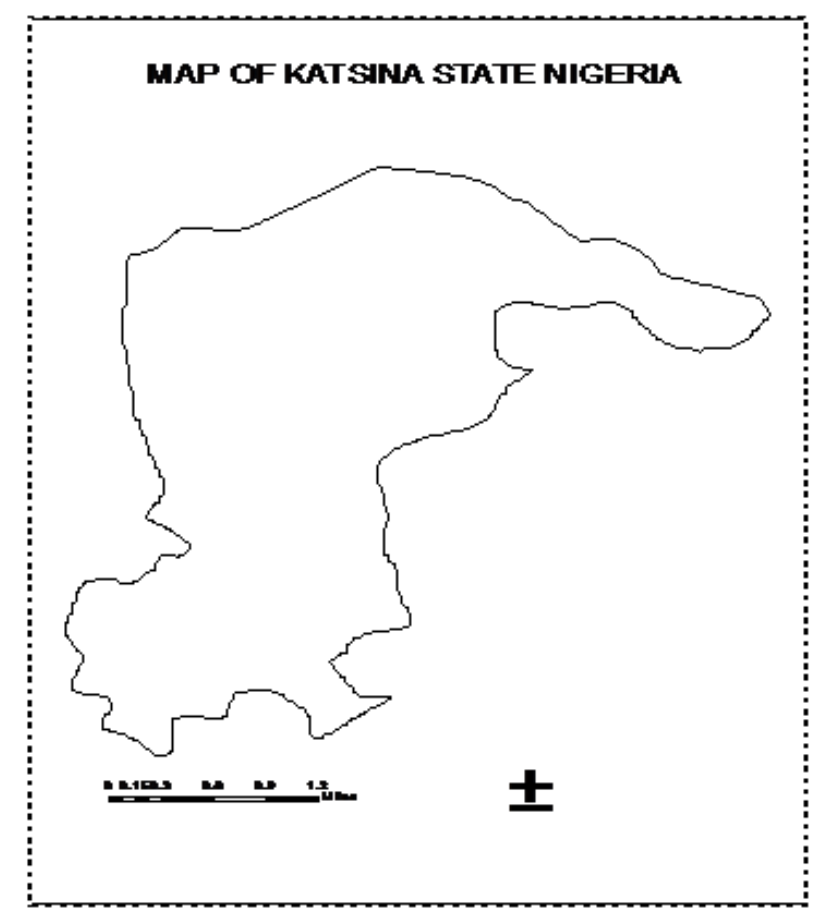

Figure1. Outline Map of the Study Area 


\subsection{Methods}

PAR model ways employed to evaluate the disaster trend in the study area; we put emphasis on the dynamic pressure and unsafe condition in the progression of vulnerability for social production of vulnerability to evaluate the disaster risk as asserted by Wisner et al., (2008). The progression of vulnerability is accompanied by root causes which is the function of political instability the country general and the state in particular have experienced in past, corruption that lead to inadequate basic facilities like cooking and lighting fuels. The dynamic pressure encompasses frequent deforestation, migration to more safe and favorable locations which caused population changes and the basic forces for livelihood. The unsafe conditions describe how livelihoods are at risk due to imbalances and low income which eventually translate in to households and risk. These conditions transform to disaster mainly fire outbreak and insecurity as contain in the model schema from Figure 2 below;

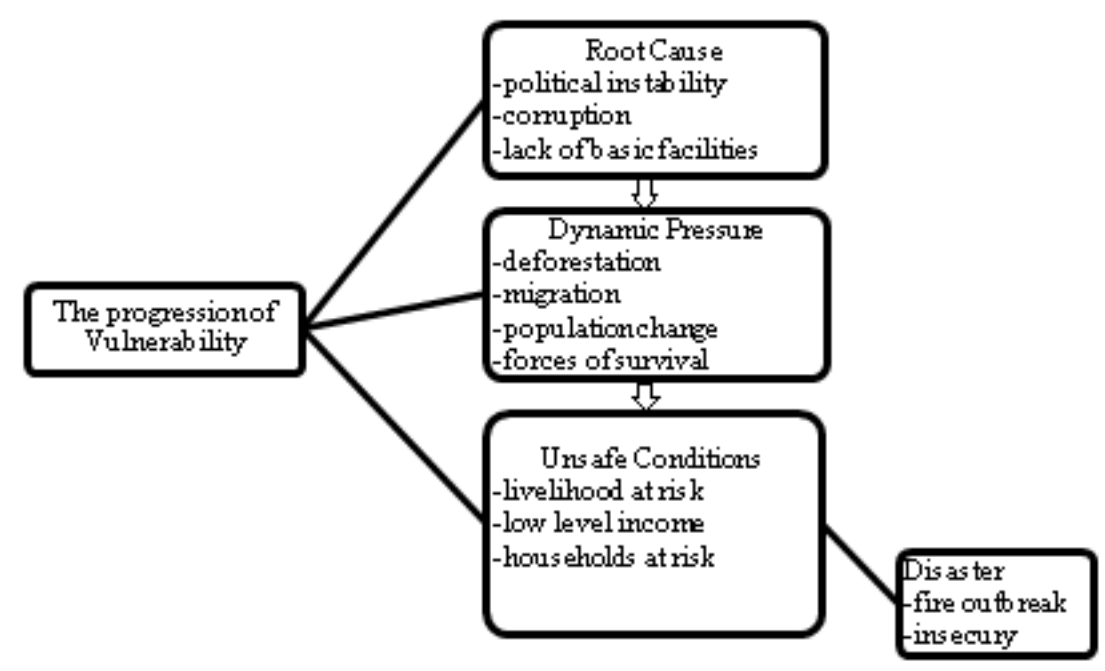

Figure2. Pressure and Release Model Schema

\subsection{Location Quotient (LQ)}

Location quotient has been used as a spatial indices for measuring spatial concentration of an activity and is the most extensively used by geographers (Shaw and Wheeler 1994). LQ is given in Equation (1) below;

$$
L Q=\frac{(X i / X)}{(Y i / Y)}
$$

Where

$X_{i}$ share in a given activity $i$

$X$ total share in an area

$Y_{i}$ gross share in an activity $i$

$Y$ total gross share

If $L Q>1$, this indicates a high spatial concentration of an activity i compared to the average share of each activity.

If $\mathrm{LQ}=1$, the activity population has a share of the total in accordance with its share of the base.

If $L Q<1$, the activity population has less of a share of the total than is more generally found in the study Area.

\section{RESULTS AND DISCUSSIONS}

\subsection{The Progression of Vulnerability (PAR Model)}

The root cause in the progression of vulnerability is the function of political instability, coupled with awful corruption and lack of basic infrastructures. The series of military inversion in the political system in Nigeria and Katsina state as well has hindered the general socio-economic developments, which has been pervasive into adequate provision of cooking and lighting fuels. The current status of 
distribution of regular households by main type of cooking and lighting fuels shouldn't have been how they are, if there was steady political system. This has invariably persuaded chronic corruption among politicians even after the ceased political power by the military. Whenever households are deprived of their civic rights, they are forced to live in vulnerable condition and striving to adopt any available means for livelihood to continue. Quality and affordability of cooking and lighting fuels were made a hot cake mainly erratic and the infrastructure dilapidated causing unpleasant condition full of fear and uncertainties. This situation develop feelings of marginalization by households, which eventually generate source of vulnerability as suggested in three ways by Wisner et al., (2008), first when households can only afford livelihoods with resources un-commendable, their actions will most likely generate vulnerability. Secondly, they tend to be neglected from authorities simulations aimed to deal with mitigation measures. Finally these types of households tend to cease trusting their self protection measures and lose belief in their own local knowledge.

Dynamic pressure implies processes and activities such as deforestation as a result of continued cutting of trees for firewood, migration in search of safer location for the satisfaction of human needs, population change in terms of changing gender roles and changes in roles characterized by age and the basic forces of survival like food and shelter. These interpret the upshots of root causes both over time and space into unsafe conditions the households using aforementioned cooking and lighting fuels vulnerable to in the study area, there are more instant, guessing existances of general underlying political and socio-economic rhythms that apparently trigger the unsafe situations. It however serve as medium through which the root cause particular forms an unsafe conditions that then have to be considered in relation to the different type of hazard facing people such as fire outbreak, deforestation which could cause desertification as such food shortage hence hunger and low income. The function of dynamic pressure in relating root causes into unsafe conditions lead to the precise description of how the pressures interact temporally and spatially, and interns of bourgeoisie and proletarians.

The unsafe conditions are the particular forms such as livelihood at risk of difficulties to cope with local needs, low level income which could not adequately sustain basic needs and eventual rendered the households vulnerable to hazard, these define the vulnerability of a population over time and space in collaboration with the hazard herein. These are therefore, proves households adopting the available main types of cooking and lighting fuels are vulnerable to disaster in Nigeria.

\subsection{Location Quotient (LQ)}

The LQ for cooking fuel $>1$ revealed a high spatial concentration of Gas, Electricity and Solar 2.45, 1.64 and 1.29 respectively in the study area compared to the average share of each cooking fuel type. Meanwhile, LQ for cooking fuel $<1$ kerosene 0.62 and other 0.83 as contained in Table 2, have less of a share of the total than is more generally found in the study area. In a similar vein, LQ for lighting fuel $>1$ indicates high spatial concentration of kerosene 1.14 in the study area compared to the average share of each lighting fuel type. The calculated LQ for lighting fuel < 1 Solar 0.89, Electricity 0.78 and Gas 0.52 have less share of the total than is more generally found in the study area. Other with $\mathrm{LQ}=1$ shows share similar to overall total share of lighting fuel types in the study area.

Table2. Location Quotient of Cooking and Lighting Fuels in Katsina State

\begin{tabular}{|l|l|c|l|c|l|}
\hline Demographic Variable & Cooking Fuel & $\boldsymbol{L Q}$ & Lighting Fuel & $\boldsymbol{L Q}$ & Total Variables \\
\hline Electricity & 185199 & 1.638 & 249776 & 0.777 & 434975 \\
\hline Gas & 25312 & 2.448 & 14842 & 0.517 & 40154 \\
\hline Kerosene & 139926 & 0.616 & 735408 & 1.136 & 875334 \\
\hline Solar & 3130 & 1.286 & 5981 & 0.887 & 9111 \\
\hline Other & 1888 & 0.833 & 5874 & 1.000 & 7762 \\
\hline
\end{tabular}

There are prevalence of high spatial clustering of Gas and Electricity (the top two with high $L Q$ values $>1$ ) in the study area taking cognizance of the five cooking fuel types used for the purpose of this research. This implies high degree of vulnerability to fire outbreak due to gas explosions and electric sparks. The widespread type of lighting fuel is kerosene using bush lamps, this cause prevailing living darkness and trail connected insecurities that guaranteed vulnerability.

\section{CONCLUSiON}

The advent of PAR model for disaster management has awakened researchers for utilization more in to natural occurrences such as climate change. The model considers disaster as the product of 
processes generating vulnerability and the natural hazard events hence question arise if disaster never happen as a result of human demographic composition leading to households being at risk. It is an intriguing attempt fostering answer to such question, though efforts were made in incorporating demography by pondering sustainable livelihood in post disaster recovery plan. Disaster management is composed of pre-disaster phase, during disaster phase and the pos-disaster phase. These disaster management scenarios used to streamline research with pre-disaster phase being most stunning phase which if well organized usually prevents the occurrence of second or both remaining phases.

The progression of vulnerability evaluated indicates forces of political instability, corruption and lack of basic infrastructures, were the causes of inadequate provision of cooking and lighting fuels in Katsina state. The trend has persuaded persistence corruption among politicians even after the civilian take over power. This has made households feels somewhat marginalized and forced to live in vulnerable condition. There are unpleasant conditions with enormous fear and uncertainties. There are continued cutting of trees for firewood, migration in search of safer location for the satisfaction of human needs, population change in terms of changing gender roles and changes in roles characterized by age and the basic forces of survival like food and shelter. These interpret the upshots of root causes both over time and space into unsafe conditions the households using aforementioned cooking and lighting fuels vulnerable to in the study area. The unsafe conditions are the particular forms such as livelihood at risk of difficulties to cope with local needs, low level income which could not adequately sustain basic needs and eventual rendered the households vulnerable to hazard, these define the vulnerability of the households over time and space in collaboration with the hazard herein. These are therefore, proves households adopting the available main types of cooking and lighting fuels are vulnerable to disaster in Katsina state.

The calculated location quotient result revealed high spatial clustering of Gas $L Q 2.45$ and Electricity $L Q 1.46$ (the top two with high $L Q$ values $>1$ ) in the study area taking cognisance of the five cooking fuel types used for the purpose of this research. This implies high degree of vulnerability to fire outbreak due to gas explosions and electric sparks. The widespread type of lighting fuel is kerosene $L Q 1.14$ using bush lamps, this cause pervasive living in darkness by the households and trail connected insecurities that guaranteed vulnerability.

This research has implication in disaster control and management, crime prevention and controls as well a good literature in the academia. Location quotient only indicates the concentration of an activity in a geographical area, it doesn't account whether the observed pattern is one of complete spatial randomness, and we therefore recommend incorporating a GIS pattern analysis for both analyzing pattern and mapping cluster. The enactment of legislations to cutback indiscriminate felling of trees for fuel wood is recommended to be preceded by alternative sources such as provision of steady electricity for safe cooking and lighting.

\section{REFERENCES}

[1] Alexander, Bob, Catherine Chan-Halbrendt, and Wilmar Salim. 2006. Sustainable livelihood considerations for disaster risk management: implications for implementation of the Government of Indonesia tsunami recovery plan. Disaster Prevention and Management: An International Journal 15 (1):31-50.

[2] Audu, EB. 2013. Fuel wood consumption and desertification in Nigeria. International Journal of Science and Technology 3 (1):1-5.

[3] Awal, MA. 2015. Vulnerability to disaster: pressure and release model for cheteclage hazards in Bangladesh. Int. J. Environ. Monit. Prot 2 (2):15-21.

[4] Barbarosoğlu, Gulay, and Yasemin Arda. 2004. A two-stage stochastic programming framework for transportation planning in disaster response. Journal of the operational research society 55 (1):43-53.

[5] Blaikie, P, T Cannon, I Davis, and B Wisner. 1994. Disaster Pressure and Release Model. At Risk: Natural Hazards, People's Vulnerability, and Disasters:21-45.

[6] Boano, Camillo. 2009. Housing anxiety and multiple geographies in post-tsunami Sri Lanka. Disasters 33 (4):762-785.

[7] Chama, CM, and HU Na'Aya. 2002. Severe burn injury in pregnancy in Northern Nigeria. Journal of Obstetrics and Gynaecology 22 (1):20-22.

[8] Davidson, Colin H, Cassidy Johnson, Gonzalo Lizarralde, Nese Dikmen, and Alicia Sliwinski. 2007. Truths and myths about community participation in post-disaster housing projects. Habitat international 31 (1):100-115. 
[9] Füssel, Hans-Martin. 2007. Vulnerability: A generally applicable conceptual framework for climate change research. Global environmental change 17 (2):155-167.

[10] Ingram, Jane C., Guillermo Franco, Cristina Rumbaitis-del Rio, and Bjian Khazai. 2006. Post-disaster recovery dilemmas: challenges in balancing short-term and long-term needs for vulnerability reduction. Environmental Science \& Policy 9 (7):607-613.

[11] Kennedy, Jim, Joseph Ashmore, Elizabeth Babister, and Ilan Kelman. 2008. The meaning of 'build back better': evidence from post-tsunami Aceh and Sri Lanka. Journal of contingencies and crisis management $16(1): 24-36$.

[12] Lyons, Michal. 2009. Building back better: the large-scale impact of small-scale approaches to reconstruction. World Development 37 (2):385-398.

[13] Nakabayashi, Itsuki, Shin Aiba, and Taro Ichiko. 2008. Pre-disaster restoration measure of preparedness for post-disaster restoration in Tokyo. J Disaster Res 3 (6):407-421.

[14] NAN. 2017. N. Nigeria's Power Generation Drops to 2,662MW.

[15] NPC. 2009. 2006 POPULATION AND HOUSING CENSUS OF THE FEDERAL REPUBLIC OF NIGERIA. Abuja: NPC.

[16] Oliver-Smith, Anthony. 1991. Successes and failures in post-disaster resettlement. Disasters 15 (1):12-23.

[17] Oyedepo, S. O., R. O. Fagbenle, S. S. Adefila, and S. A. Adavbiele. 2014. Performance evaluation and economic analysis of a gas turbine power plant in Nigeria. Energy Conversion and Management 79:431440.

[18] Peck, Michael D., Gerebreg E. Kruger, Anna E. van der Merwe, Wijaya Godakumbura, and Rajeev B. Ahuja. 2008. Burns and fires from non-electric domestic appliances in low and middle income countries: Part I. The scope of the problem. Burns 34 (3):303-311.

[19] Peeta, Srinivas, F. Sibel Salman, Dilek Gunnec, and Kannan Viswanath. 2010. Pre-disaster investment decisions for strengthening a highway network. Computers \& Operations Research 37 (10):1708-1719.

[20] Shaw, G., and D. Wheeler. 1994. Statistical Techniques in Geographical Analysis: David Fulton.

[21] Sheu, Jiuh-Biing. 2007. An emergency logistics distribution approach for quick response to urgent relief demand in disasters. Transportation Research Part E: Logistics and Transportation Review 43 (6):687-709.

[22] Wisner, Ben, Piers Blaikie, Terry Cannon, and Ian Davis. 2008. At Risk: Natural Hazards, Peoples Vulnerability and Disasters. 2nd ed. USA: Routledge.

[23] Yi, Wei, and Arun Kumar. 2007. Ant colony optimization for disaster relief operations. Transportation Research Part E: Logistics and Transportation Review 43 (6):660-672.

[24] Yi, Wei, and Linet Özdamar. 2007. A dynamic logistics coordination model for evacuation and support in disaster response activities. European Journal of Operational Research 179 (3):1177-1193.

Citation: Murtala Rabiu, et.al. "Cooking and Lighting Fuels Clusters in Katsina: Progression of Vulnerability Dread on Households”. International Journal of Research in Geography. vol 5, no. 1, 2019 , pp. 27-33. doi: http://dx.doi.org/10.20431/2454-8685.0501003.

Copyright: (c) 2019 Authors. This is an open-access article distributed under the terms of the Creative Commons Attribution License, which permits unrestricted use, distribution, and reproduction in any medium, provided the original author and source are credited. 